\title{
"An Action Research on Keyword and Semantic Mapping Strategies of Vocabulary Learning and Retention by EFL Tenth - Grad Students in Jordan"
}

\section{Dr. Mwaffag Mohammad Khaled Shatnawi \\ Abstract}

The purpose of this study was to investigate the effect of two vocabulary strategies; keyword and semantic mapping, on English vocabulary learning and retention of the tenth-grade Jordanian students. The subjects of the study consisted of 90 male students from Howarah Secondary School. They were divided into three groups: two experimental and one control. To guarantee the equivalence and homogeneity of the different groups, the researcher administered a test in English language at the beginning of the first semester of the academic year 2011/2012. Afterwards, each experimental group was taught according to one of the vocabulary teaching strategies (keyword or semantic mapping), while the control group was taught in the traditional way for five days. After finishing the instructions, all the groups sat for a learning test. Then, after two weeks, the groups sat again for the retention test. To describe and analyze the data gathered, means, standard deviations, one-way ANOVA and Tukey Multiple Comparison for the Means were used. The findings of the study indicated that there was a significant difference between the mean scores of the students in the keyword group, semantic mapping group and control group on the learning test in favor of the keyword group. However, there was no significant difference between the mean scores of the students in the three groups in the retention test. In the light of these finding, the researcher recommended that the teachers should give greater recognition to the importance of strategy training, by introducing various vocabulary strategies such as keyword and semantic mapping. The researcher also recommended further research to investigate the effect of the same strategy with different ages and levels of proficiency.

Key Words: Vocabulary, Keyword strategy, Semantic mapping strategy, Learning, Retention.

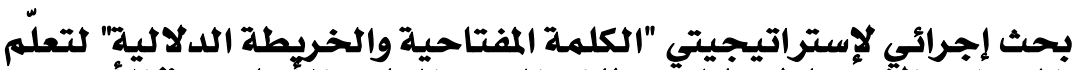

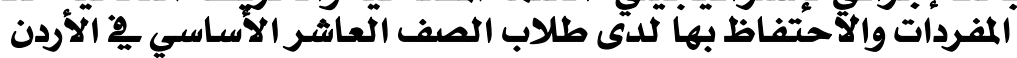

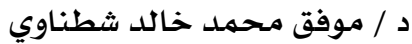

$$
\begin{aligned}
& \text { جامعة الإمـام محمدل بن سعود الاسلامية كلية ملية الشريعة الإحساء } \\
& \text { قسم اللغة الإنجليزية }
\end{aligned}
$$

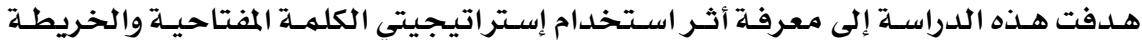

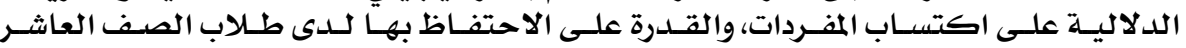

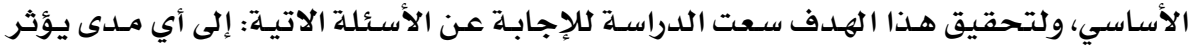

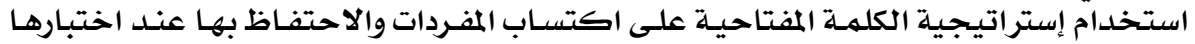

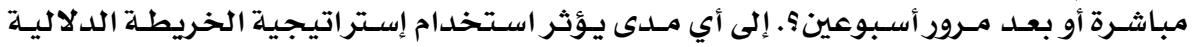

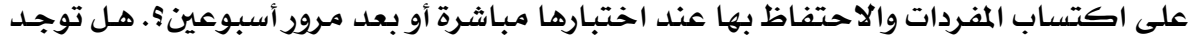

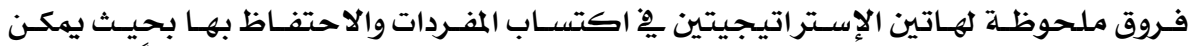

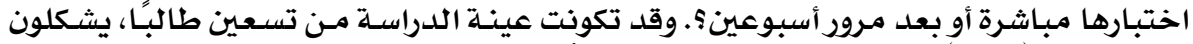

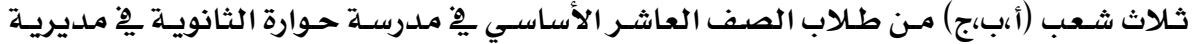




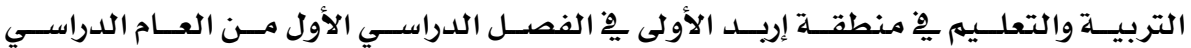

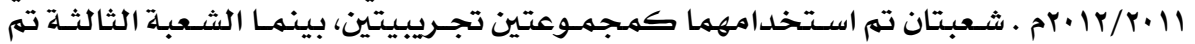

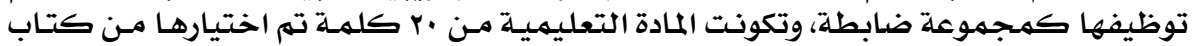

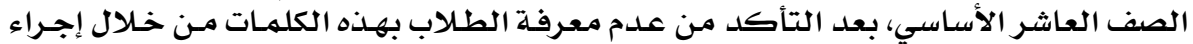

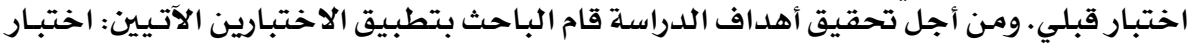

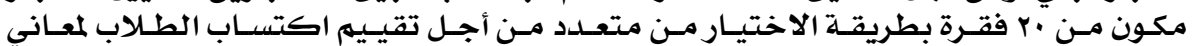

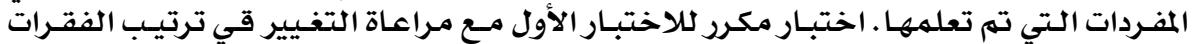

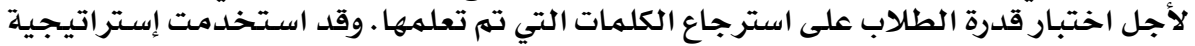

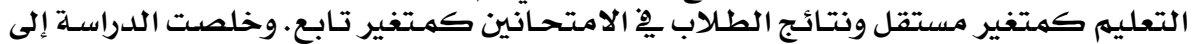

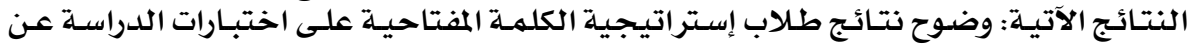

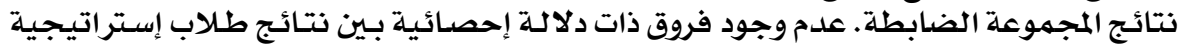

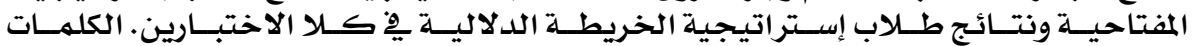

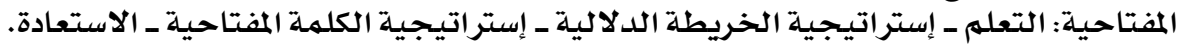

\section{- Introduction}

- Background of the study

"Vocabulary is an essential mean of interchanging ideas and of acquiring new experiences and mans' growth in ideas has always been accompanied by a corresponding expansion of his vocabulary" (Gray 1939, p: 1).

It is widely agreed upon nowadays that to learn English or any other language as a foreign or second language; one has to set oneself to the task of acquiring a significant portion of the lexicon. A lexical word is the foundation of every native speaker's fluency and idiomaticity (Powley and Syder, 1983). Foreign language learners have to develop a good language vocabulary so as to make sense of what they hear and read, and to express themselves fluently and appropriately. After decades of neglect, vocabulary has been considered central to any language acquisition process, native or non-native (Laufer, 1997).

Vocabulary knowledge is important because it encompasses all the words we must know to access background knowledge, express ideas, communicate effectively, and learn about new concepts. "Vocabulary is the glue that holds stories, ideas and content together and makes comprehension accessible for children, (Rupley, Logan and Nichols, 1999). The knowledge of vocabulary is so broad and wide that it is unwise to present all aspects once to students especially to low achievers. Presentation of vocabulary in the way that focuses on form and meaning with the help of visual and audio aids as well as the crutch of L1 seems to be more advisable (Cock, 1996).

\section{0}


It is important to know how lexical items are processed in the brain. There are different explanations concerning the mental process when learning lexical items. To know a word, it must be obtained, stored, retrieved and used (Rubin, 1987). Levin, Levin, Glasman, and Nordwall, (1992) make a little bit change to this and develop a $3 R$ approach: "Recodes, Relates, Retrieves." Through this 3R approach, memory is being, mainly, stored and kept in the brain. The significance of the audio and visual aids involvement, and the importance between form and meaning interaction are added by Brown and Payne (cited in Fan, 2003:223). Nation (2001) mentions that there are three important processes that may lead to any lexical item being remembered. These involve noticing, retrieval and creative use. According to Nation (2003:63) motivation and interest are considered as important conditions for noticing. So English teachers should present the lexical items in a way to draw the students' attention and arouse their interest. A variety of vocabulary strategies can be used successfully if the students feel the importance of learning the lexical items.

Vocabulary has played a major role for the Jordanian students to learn and master English as in listening, speaking, reading, and writing of English out of insufficiency of English vocabulary. English teachers have difficulties in helping students comprehend grammar rules and apply them mainly because of the students limited commend of vocabulary.

It is found that the amounts of vocabulary are closely related to the effect of instructions in the classroom (Krashen and Terrell, 1983). How to help students acquire the optimal amount of vocabulary with the least amount of time and effect has long become the challenging task for most native and non-native English teachers (Levin, Levin, Glasman and Nordwall, 1992; McKeon and Beck, 1988; Meara, 1992).

The ability of mastering vocabulary skills is considered one of the learning goals in the Jordanian English Curricula. In the lower basic stage, teachers are required to help students develop phonic skills and use realia to facilitate the integrative use of language. In the upper basic stage, teachers are expected to develop dictionary skills. It is stated that Jordanian English teachers should avoid exaggerated use of dictation. In the secondary stage, it is indicated that vocabulary learning is built through meaningful context. English teachers should 
use language tasks and risk taking in language learning (General Guidelines and Curricula for the Basic and Secondary Stage, 2002).

The size of vocabulary, Jordanian students should achieve to read and understand simplified and authentic English texts, is about 5000 words: 1000 words for the lower basic stage; 2000 words for the upper basic stage, and about 2000 words for the secondary stage (General Guidelines and Curricula for the Basic and Secondary stages, 2002). Nation (1993) suggests that the size of vocabulary the learner should have to carry out meaningful and successful conversation is up to 5000 words. This wide gap between the suggested vocabulary size (5000 words) and the actual vocabulary size of foreign language learners in Jordan (1000-5000) is noticeable and needs an urgent quick remedy. A vocabulary of that size, say 2000 words for the upper basic stage is not sufficient for functional language proficiency since there is a general consensus that 5000 base words is a minimal requirement for any learner's level (Laufer, 1997, Nation 1990). It is therefore necessary that a large number of words should be learned in a short period of time at the low-high basic stages and secondary stages of language learning. Since the time available for the learning of the large number of new words is limited in our English curricula, it is essential to tackle this problem systematically, both in selecting the relevant vocabulary and in creating optimal conditions for the learning process. Jordanian students have been criticized for their insufficient vocabulary items. This limited vocabulary of Jordanian students shows that there is a wide gap between the pedagogical and the actual learning situation of the Jordanian students. It is worth mentioning here that there is a strong general trend towards using World Wide Web in teaching vocabulary.

\section{- Statement of the Problem}

Vocabulary has played an important role for Jordanian learners to master English as a foreign language. Many students get frustrated in listening, speaking, reading, and writing of English because of the insufficiency of English vocabulary. English teachers face difficulties in helping students comprehend syntactic rules and apply them mainly because their students have limited control of vocabulary. The researcher has observed that the students have a problem in acquiring vocabulary items. The students also face a problem in retaining vocabulary items to express themselves in a given situation. The researcher believes that the inappropriate and insufficient strategies 
used by EFL teachers hinder, in a way or another, the learners' acquisition of adequate vocabulary items which are essential for the communication process. So, the researcher will conduct this study to evaluate the effectiveness of two strategies: Keyword and semantic mapping on vocabulary learning and retention.

\section{- Significance of the Study}

The literature on the efficacy of the keyword and semantic mapping strategies is extensive and growing fast but few compare these two strategies in a natural sitting. More evidence on the effectiveness on keyword and semantic mapping strategies under natural sitting is needed. The keyword and semantic mapping strategies are considered as popular vocabulary teaching strategies, but their relative effectiveness has not been studied and examined thoroughly enough. Also, the researcher finds that there is not a similar study being conducted at the local level to examine and find out the effectiveness of these two strategies, keyword and semantic mapping, on the tenthgrade students acquisition and retention of vocabulary items. Beside, the related literature which investigates the keyword and semantic mapping strategies primarily involves non-Arab learners and more support on their efficacy on Arab foreign language learners vocabulary acquisition, specifically the Jordanian learners, is desirable. Consequently, the researcher believes it is important to carry out the present study to examine the efficiency of keyword and semantic mapping as two innovative vocabulary strategies in enhancing students' learning and retention of vocabulary items in a normal classroom. The researcher also hopes to reach finding and suggest practical implications that can improve strategies used in teaching and learning vocabulary items. So the study is an attempt to find out to what extent Jordanian students can get a benefit from teachers who use innovative vocabulary strategies and satisfy their needs.

\section{- Ouestion of the Study}

This study aims at answering the following questions:

1. To what extent does Jordanian tenth-grade students' use of keyword strategy affect their learning and retention of vocabulary items either immediately or after two weeks?

2. To what extent does Jordanian tenth-grade students' use of semantic mapping strategy affect their learning and retention of vocabulary items either immediately or after two weeks?

\section{3}


3. Are there any significant differences between teaching words using keyword and semantic mapping on students' learning and retention of vocabulary items either immediately or after two weeks?

\section{- Definition of Terms}

- Keyword strategy:

Keyword strategy is a strategy which is designed to facilitate memory retention of new words with their meanings. It combines the use of visual imagery and sound similarities between known and new words. It usually involves using a specific word in the learners' familiar language, either L1 or L2, to form an acoustic and imagery link between the target word and the familiar word (Atkinson and Raugh, 1975).

\section{- Semantic Mapping:}

Semantic mapping is a strategy in which words are categorically structured in a graphic or visual form. This strategy helps students to make a connection between new vocabulary and prior knowledge, to see the relationships among ideas and develop word knowledge (Nagy, 1997).

\section{- Acquisition:}

Acquisition is the mental process through which learners develop their abilities to understand and use languages as well as description of the stage which they pass in acquiring a language (Nunan, 1990).

\section{- Retention:}

It is the extent to which the subject still remembers and keeps the newly learned words.

\section{- Strategy:}

It is the application of an approach in acquiring new vocabulary items either consciously or not.

\section{- Vocabulary learning:}

It is the process by which any learner can understand the meaning of given lexical item and use it.

\section{- Limitations of the Study}

The generalization of the findings of this study is limited by the following factors:

1. This study was restricted to the tenth-grade students in Howrah Secondary school for boys in Irbid, the First Directorate of Education.

\section{4}


2. Evaluating students' vocabulary learning and retention was restricted to the two chosen vocabulary strategies which were adapted by the researcher.

3. The researcher developed the vocabulary learning and the retention tests.

\section{- Review of Related Literature}

There has been a considerable debate about the most effective teaching vocabulary strategy to develop learners' vocabulary as shown by the increasing amount of studies on vocabulary teaching strategies. A great number of vocabulary teaching strategies has been developed and empirically tested since 1970s.

Keyword and semantic mapping strategies, two innovative vocabulary teaching strategies, were examined on learners learning and retention of the vocabulary items being taught.

The first group of studies of the vocabulary teaching strategies mentioned here were those which examined the use and efficiency of keyword strategy for lexical items learning and retention. Another group of studies and investigations reported on the effectiveness of semantic mapping strategy on vocabulary learning and retention.

\section{- The Keyword Strategy}

The origin of the keyword strategy is unknown. Desrochers and Begg (1987) placed it between the 13th and 19th centuries. In modern times, psychologists as Atkinson and Rough (1975) renewed interest in this strategy and claimed to have coined the expression keyword strategy (1975). Atkinson and Raugh (1975) divided the learning of new items, using keyword strategy, into two stages:

1. The learner selects native-language word (i.e keyword) which is phonologically and/ or orthographically similar to the foreign language word. This stage is referred to as the acoustic link.

2. The learner creates a mental image that associates the keyword referent with the native-language translation of the foreign language word. This stage is called the imagery link. So the keyword strategy establishes both a form and a semantic connection (using images) between the foreign language word and its L1 translation (Atkinson and Raugh, 1975).

The keyword strategy is probably one of the most researched strategies for vocabulary acquisition (Desrochers and Begg, 1987;

\section{5}

Journal of Arabic Studies in Fducation \& Psychology (ASEP) 
Nation, 2001). In fact, numerous studies have set out to investigate its efficiency and few studies have obtained conflicting results. Many studies investigated the immediate and delayed memory effect of the keyword strategy. Some studies revealed that keyword strategy was better only for immediate recall (Wang, Thomas and Cuellette, 1992); Some studies indicated its benefits for both immediate and delayed recall (Pressley Levin and Delaney, 1982; Avila and Sadoski, 1996); while others showed it had no significant effect on immediate recall nor delayed recall (Van Hell and Candia Mahn, 1997).

Raugh and Atkinson (1975) conducted four experiments to evaluate the effectiveness of two-stage procedures (The keyword strategy) in learning second language vocabulary. In those experiments, the keyword strategy was compared to various control Spanish for learning Spanish vocabulary items. The findings of all of the experiments proved that the keyword strategy was highly effective, yielding in one experiment. For example, in a finale test, the keyword group scored $88 \%$ while the control group scored $28 \%$.

Atkinson and Raugh (1975) examined the effect of the keyword strategy on the acquisition of Russian vocabulary items. Subjects of this study were fifty-two Stanford University undergraduate. All of the subjects were native speakers of English who had not studied Russian at all and had not participated in experiments using the keyword strategy. Learners were given instruction on the use of the keyword and practiced a list of thirty words. After that, subjects were randomly assigned to the experimental and control groups. On all of the measures, the keyword strategy proved to be highly effective yielding for the most critical test given to those students. The keyword strategy group scored $72 \%$ whereas the control group scored $40 \%$.

Pressley, Liven, Hall, Miller, and Berry (1980) examined the effect of the keyword strategy on foreign word acquisition. They conducted four experiments to achieve this purpose. Based on these experiments, the keyword strategy had proved to be superior.

Johnson, Adam, and Burning ( 1985 ) conducted a study of undergraduate students recall of words. Students were asked to use various learning strategies including the keyword strategy, for both immediate and delayed recall. The finding of the study showed that the keyword strategy facilitated the immediate recall of concrete lexical items. It was concluded that the keyword strategy had little value for the long-term retention of abstract words. 
Trout ( 1987 ) conducted a study to investigate how method of instruction for college students, keyword strategy versus a traditional one was related to acquisition and retention of medical terminology in classroom setting and in individualized learning. The sample of the study consisted of 120 college students. The sample was taught three lessons of medical terminology using one of the following strategies; traditional, keyword in a classroom and keyword in individualized learning. The results indicated that the class which was taught to use the keyword strategy retained significantly more words than traditional strategy group for the immediate test of medical terminology. The study also indicated that there was no significant difference in long-term retention of medical vocabulary items at four and eight weeks between traditional and keyword strategies.

Hall ( 1988 ) conducted three experiments to examine the use of the keyword strategy for vocabulary learning. In the first experiment, the researcher gave university students an extensive training of the use of keyword strategy. Then the students were asked to study and recall the English equivalents of German nouns before and after the keyword under different conditions of presentations. It was found that learning was better after training than before training. In the second experiment, the students were giver brief definition of unusual with self-paced presentation. Results of this experiment revealed tha the keyword subjects scored higher than control group subjects with vocabulary selected to suit the keyword strategy. Furthermore, the finding of the keyword subjects were poorer than those of the control subjects especially on items not selected to suit the keyword strategy. Finally, the finding of the third experiment showed that there was no difference between the generated versions of the keyword strategy in experiment one; and the keyword strategy proved to be more effective if it is used in conjunction with several lists of presentations.

Brown and Perry (1991) conducted a study on six intact ESL classes of Arabic speaking students in order to compare three learning strategies; keyword, semantic, and keyword-semantic strategies for acquiring ESL vocabulary. The subjects who were divided into three groups, received four days of instructions. Recognition and cued-recall tests were used to measure the treatment's effectiveness for both one day and nine days later. The results of the immediate test after the treatment revealed that 
the keyword strategy facilitated vocabulary acquisition for lowerproficiency students .

According to the delayed results for both the recognition and cued-recall test, it was suggested that the combined keywordsemantic strategy increased vocabulary retention than using keyword strategy alone.

Wang and Thomas (1992) conducted two studies so as to compare the effects of imagery based instruction and rote learning on the long term retention of English translation of Chinese ideographs. The researchers manipulated the factors of time (immediate after a day of instruction versus delayed test after nine days) and learning strategy (keyword versus rote learning). The finding revealed that the learners who received imagery instruction exhibit greater retention in the immediate test but showed poorer retention in the delayed test. It was also indicated that the experiments supplying encoding were not really effective as subject generated encoding. The two studies also suggested that the main purpose of the instruction in the use of memory and imagery devices should enable learners discover imagery devices cues and be able to apply them.

Levin et al. (1992) compared the keyword strategy to various alternative vocabulary learning strategies. One of these strategies was sentence-context. The sample included third, fourth, seventh and eighth grade students in the Pacific Southwest Schools. The results showed the superiority of keyword strategy over the context strategy. Several studies have proved the effectiveness of using keyword strategy in vocabulary acquisition and retention for different spans of time.

Abu-Khadrah (1995) investigated the efficiency of three ESL vocabulary strategies. These strategies were keyword, translation and context. The sample of the study consisted of 70 tenth-grade students enrolled in three classes. Every class was subjected to one of these strategies. The keyword strategy group scored higher than those in the other two strategies in the immediate test. It also showed that keyword strategy group's results in the test given after two weeks were higher than the results of those in the other two strategies. In other words, there were differences among the keyword strategy, context strategy and translation

\section{8}


strategy in favor of the keyword strategy on the test given immediately after the treatment and fourteen days later. The finding of the study showed the effectiveness of keyword strategy over both translation and context strategies.

Avila and Sadoski (1996) explored new applications of the keyword strategy to acquire English vocabulary items. The researchers selected sixty-three fifth grade limited English proficiency students from an urban school district in Texas. The sample was divided into two groups: an experimental group using keyword strategy and a control group. The findings of the study revealed that the keyword strategy group outperformed the control group. The study also revealed a significant main effect for retention interval.

Abdel-Majeed (2000) investigated the use of the keyword strategy in a normal classroom situation. He selected 90 Arab students; 45 were taught the definition of 20 non-frequent English words and nonsense words using the keywords method, while the other 45 students were used as the control group. The researcher administered two tests: an immediate recall test and a delayed recall test which was administered two weeks later. The findings revealed that the keyword group outperformed the control group in both acquisition and retention.

Shapiro and Waters (2005) investigated the cognitive process underlying the keyword strategy of foreign vocabulary learning. A total of 104 students were tested in a 2 (imagery levels) $\times 2$ (processing strategy) mixed design. Each subject was asked to memorize 30 Latin vocabulary words and they were told that they would later be asked to recall word meaning. The subjects who were enrolled in an introductory psychology course at the University of Massachusetts, were divided into two groups. The first group was provided with both the keyword and its image while the other group was instructed to use its own keywords. After finishing the instruction, the researcher administrated a districted test. Then after a week, a delayed test was also administrated. The findings revealed that there was a significant main effect of given imagery strategy in the immediate and delayed tests.

Ching-Chung (2006) explored the effect of a new keyword strategy on learning vocabulary items for Chinese students. The 
sample of the study consisted of one hundred and twenty students of Junior College graduates. They have roughly learned English as a foreign language for eight years. Their average age was between 20-21 years old. About 18 new English words (arranged in groups) were learned by either keyword strategy, or by direct translation and memory. A task was administrated either immediate after the treatment or after a week. The finding revealed that both keyword strategy groups made superior performance on acquisition and retention.

However, there were many studies which showed that keyword strategy has no effect either on immediate or delayed recall test. Whillerman and Melvin (1979) conducted a study to find out the differences in the number of words recalled either immediately after the instruction or after a month. The sample of the study consisted of undergraduate students of French who each received a list of 20 words. The subjects of the study were 95 students; 52 males and 43 females enrolled in six sections of the elementary French course taught at the University of Texas at Austin. The sample was divided into two groups. The first group was instructed to use the keyword strategy, while the other group had to use the rote-learning strategy. Two tests were administrated: the day after the instruction and a month later. The finding revealed that there was not any significant difference between the groups in the number of words recalled either immediately after finishing the instruction or after one month. It was concluded that language students has already developed their own effective vocabulary learning strategies.

Hogban and Lawson (1994) investigated the efficiency of the keyword strategy. The sample of the study consisted of American secondary school students who had been studying Italian for three years at least. The students were exposed to a list of 30 Italian words at a rate of one item for every 30 seconds. The results indicated that the students who used the keyword strategy showed a poorer immediate recall than did the control group. And after two weeks, the retention test showed no difference between the two groups. It was concluded that the students of that age have already developed their own vocabulary learning strategies.

\section{0}


Van Hell and Mahn (1997) examined the efficiency of the keyword strategy versus rote rehearsal in learning foreign language vocabulary in two studies. In the first study, 36 experienced Dutch students of foreign language while 40 American learners participated in the second study. All the learners were inexperienced foreign language learners. Vocabulary acquisition and retention were assessed immediately and two weeks after finishing the instruction. The finding revealed that the experienced foreign language learners of rote rehearsal group recalled better that the keyword group. In addition, the inexperienced learners in both groups recalled the same proportion of words.

Rodriguez and Sadoski (2000) conducted a study to examine the effect of rote rehearsal, context, keyword, and the combination of context and keyword strategies on immediate and long-term retention of English as a foreign language (EFL) vocabulary items. The researchers chose eight intact tenth grade EFL classes randomly. The learners had been studying EFL for more than two years. The subjects were divided to four groups. A cuedrecall test was used to examine the effect of strategies both one day and a week later after the treatment. The findings revealed that the combined context and keyword strategies produced superior recall than the keyword strategy alone after either one day or a week.

We can observe that most studies about keyword strategy revealed how effective this strategy was in facilitating learning of vocabulary items whether those words are second language vocabulary or foreign language vocabulary.

It is also indicated that the keyword strategy is more effective in immediate acquisition of vocabulary items than any other vocabulary strategy as context, translation and notebook. The keyword strategy proved to be beneficial in retrieving vocabulary items. An interesting finding is that the keyword is a motivating strategy for acquiring new vocabulary so it can be used with different ages of learners. In learning vocabulary items, a little time is required from both the teacher and the learners in applying the keyword strategy. When the keyword strategy is used with a combination with other vocabulary strategies as context strategy, great effect occurred especially that related to the long-term retention. In spite of its usefulness in the area of foreign

\section{1}


language vocabulary, few empirical studies have been conducted in this area.

\section{- Semantic mapping strategy}

The advocators of this strategy believe that the key to successful vocabulary instruction is based upon students background knowledge.

The increasing awareness of the influence of prior knowledge in the comprehension of texts has given ever greater importance to vocabulary development. When words are semantically related, it allowed exercises to examine the relationships among the instructed words and also integrate whose words with students prior knowledge about the concepts (Mezynski, 1993).

Semantic mapping is a strategy that helps students place new words in their existing schema when a connection is made among the words they already know about a specific topic. Developing semantic mapping deepens students' understanding of important vocabulary (Alber and Foil, 2002).

Semantic mapping is a diagram which helps learners see the relationship between words. Since it was developed by Hanf (1971) and being expanded by Jackson and Pearson (1998), such strategy had been used widely as a vocabulary development strategy. In fact, semantic mapping strategy was one of the teaching strategies that caught many scholars' attention. The following steps show the use of semantic mapping as a vocabulary development strategy:

Step (1): The teacher chooses an important topic which at the same time is familiar to the learners so as they can list group or related words to the topic easily.

Step (2): The teacher writes the topic on the chalkboard inside a circle. The teacher draws a chart that depends on the number of the words which the teacher needs. This chart may be expanded according to the learners' effort in giving new related words to the topic.

Step (3): The teacher motivates the learners to give more related words as possible as they can.

Step (4): As the learners learn more words or discover new relationships, they can add them to the chart on the board inside small circles.

Step (5): Teachers and students discuss the relationship between the written words on the chart. 
Figure 1 below shows an example of constructing a semantic mapping chart by the researcher of this study:

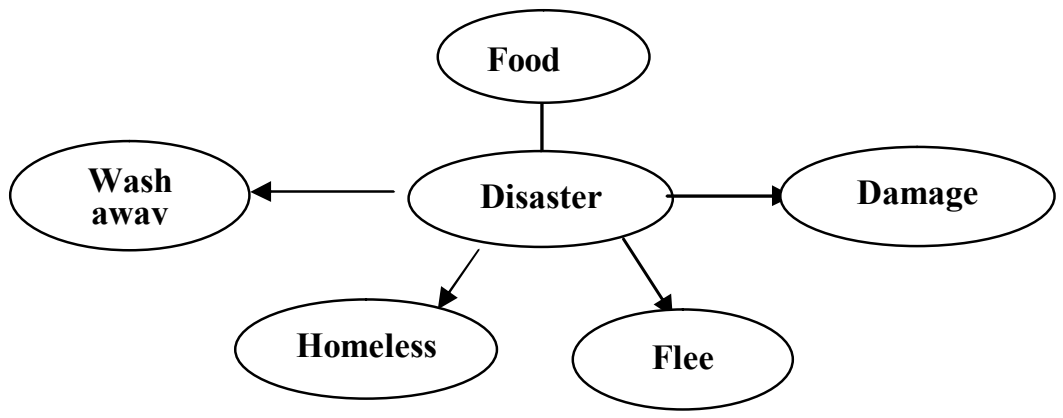

(Adapted from Johnson and Pearson, 1984)

Figure 1 is an example of constructing a semantic mapping chart.

There has been research as to which effective and efficient strategy would help the teachers and educators to teach students to acquire a well understanding of the lexical items being taught. A strategy has been claimed to have such role which is semantic mapping strategy although there were doubts about its effectiveness according to some empirical research.

Levin et al. (1984) compared three instructional strategies which are contextual analysis, semantic mapping, and keyword in order to find which one of these strategies has the most significant impact on students' recall of vocabulary items definitions. The sample consisted of 71 high- achieving fourth and fifth- grade students from four classrooms in a mixed university community in the Midwest. Posttests were administered. The researchers used four vocabulary- learning measures to examine the difference between the treatments of the high- low achievement groups. The four learning measures were: definition recall, initial vocabulary usage, delayed vocabulary usage, and definition matching. According to the definition- matching test, the lower-achieving samples scores were higher among the semantic mapping than the keyword or context analysis strategies groups. It was indicated in the study that there was place for the semantic mapping strategy although it did not produce high positive results as the other strategies.

Svenconis and Kerst (1995) investigated the effectiveness of employing semantic mapping strategy versus non-semantic mapping for learning vocabulary in a hypertext environment. The sample

\section{3}

Journal of Arabic Studies in Education \& Psychology (ASEP) 
consisted of forty-eight high school students in grades 9 through 12 . The majority of the sample was freshmen and sophomores. The sample was selected randomly from a pool of students at private high school in the Washington D.C.

1. The students who had mapping were evaluated in the context of those factors which may influence its effectiveness; Semantic structure, instructional method, and sound component. Each subject was assigned in one of four experimental groups. Two groups of the subjects studied each of three groupings of words in a word listing approach. One of the word list groups studied the groups of words without word sounding while the second had the words sounded.

2. The other two groups of the subjects studied each of three groupings of words under the semantic map format. Each group of 24 words was presented to the subjects, on one screen, in the form of semantic maps. One of the semantic map groups studied the groups of words without word sounding but the second had the words sounded for them. Multiple-choice tests were administered using the computers. The findings revealed that there was no significant main effect for the semantic mapping strategy. It also confirmed the fact that semantic mapping with sound produced superior scores than the vocabulary activities group.

Zakaria (2001) conducted a study to see whether semantic mapping would be effective in enhancing students' reading comprehension. The first group was exposed to the use of semantic mapping in reading while the control group was exposed to the conventional strategy in reading. Two tests before and after the treatment were administered. Also, the subjects were asked to respond to a questionnaire to get students perceptions towards the use of semantic mapping. The findings of the study revealed that the semantic mapping strategy group performed better than the control group. The students had positive attitudes towards the use of semantic mapping. Thus, it can be concluded that semantic mapping is effective in aiding comprehension.

It is observed that many experimental studies proved the semantic mapping strategy effectiveness in facilitating learning vocabulary items visually and directly. Using this strategy improves students' mental abilities since they are going to use them in finding the related words to the topic.

\section{4}


Unfortunately, few studies examined the effectiveness of using both strategies; keyword and semantic mapping, which might be used in teaching vocabulary in the classroom and it may yield good results. So this study attempts to examine the effectiveness of both strategies as they facilitate learning and retrieving new vocabulary items.

\section{- Method and Procedures}

- Subjects of the study

The subjects of the study consisted of 90 tenth - grade male students enrolled in EFL sections at Howarah School. All the students have been learning English as a foreign language since they were in the fifth grade. They have studied English for five years. And they have been studying in the same basic school since they were in the first grade. Their ages ranged from $15-16$ years. All the students were native speakers of Arabic. The subjects were assigned purposefully to one of the three strategies: keyword strategy $(n=30)$, semantic mapping strategy $(n=30)$, and traditional strategy (control group, $n=30$ ). They were given training on vocabulary learning strategies for five days.

\section{- Variables of the study}

The independent variable of the study is the teaching vocabulary strategy. The dependent variables are vocabulary learning and vocabulary retention tests scores.

\section{- Material}

Twenty English words shown in Appendix (A) were selected as the item were unfamiliar to the students and were not taught by the teacher before conducting this study. To ensure the unfamiliarity of the selected items, the researcher administered a 30-item definition test on the vocabulary items. On the other hand, for the sake of the keyword strategy's application, an Arabic keyword was selected for each noun, verb and adjective of the selected words. The Arabic keywords were chosen according to the following:

Firstly, the chosen words should be standard Arabic language.

Secondly, the keywords should have sound like the chosen words or have a relative sound. For example, the last syllable of the word mountaineer sounds like the standard Arabic keyword (yaseer) which means (walks). Both words have to be sued in meaningful sentence. For instance" The mountaineer walks near our farm" Finally, the keyword should be concrete verb, an adjective or a noun in a way that facilitates the imagery process by the students.

\section{5}




\section{- Instruments}

The instruments include the following:

1. A multiple-choice vocabulary test of twenty items was constructed to assess the students' learning of the 20 studied vocabulary words immediately after finishing the treatment.

2. A replication of the previous multiple-choice vocabulary test, with a change in the sentences order, was administered to examine the students' retrieval of the learned vocabulary words. On the multiple choice test, the students were asked to circle the correct word that best filled in the gap of the sentences. As Watanabe (1997) suggests, testing lexical items in context have a cuing effect on recall, which is considered an appropriate test for the learning and retention of the vocabulary items. The test papers were collected and marked by the researcher. Five scores were awarded for each correct answer.

\section{- Validity of the instruments}

To guarantee the validity of the learning and retention tests which were prepared by the researcher, they are given to three TEFL specialists at Yarmouk University in order to examine the accuracy and adequacy of the test. Their comments and views were taken into consideration and the necessary modifications (deletion, word order, and capitalization) were made accordingly. Moreover, the same tests were reviewed by two English supervisors and five tenth grade teachers to decide the test validity. Their comments were also taken into consideration.

\section{- Reliability of the instruments}

The researcher followed the following procedures to maintain a reasonable degree of test reliability:

First, the researcher chose a sample of the tenth grade students enrolled in the first semester of the academic year 2011/2012 and gave them a draft of two tests to be answered immediately and after a delay.

Second, students' answers of the two tests were computed using Cronbach alpha to examine the tests reliability. The obtained value was (0.89) for the learning test and (0.88) for the retention test. The obtained values showed good level of test reliability.

\section{- Procedures of the studv}

The researcher used the following procedures in conducting the study.

\section{6}


1. Three EFL classes ( $A, B$, and $C$ ) were assigned to two experimental groups and one control group. The keyword strategy was used with class $A$, the semantic mapping strategy was used with class (B), and the traditional strategy (control group) was used with class (C). To assess the homogeneity of the three groups, the researcher administered a test in the English language. One -Way ANOVA showed that there were no significant differences among the three groups.

2. The keyword group learners were instructed in the keyword strategy. They practiced 20 English vocabulary items so as to learn the keywords and form an image for the learned words. For example, the teacher taught the learners the word tremendous and supplied them with Arabic word that had similar sound as nas (text). Then, the learners used both words in a meaningful sentence like I read a tremendous text. Next, the teacher wrote the sentence on the board. All the keywords were given by the researcher. On the other hand, the semantic mapping sample was instructed in the semantic mapping strategy. The teacher provided the students with the topics which were going to be used as the base for the students' maps. For example, the teacher wrote earthquake inside a circle on the board. Then, he asked the learners to think of words that could be related to the topic. The learners provided the teacher with many words as damage, wash away, homeless ... etc. The students' words were presented in a diagram on the board while the control group was given the definition of the 20 items. For instance, the meaning of experiment is trial.

3. A day after the presentation of the vocabulary items, a learning test (multiple-choice), covering all 20 vocabulary items, was administered. Two weeks later, the retention test (the replication of the multiple-choice test with a change in the order of the sentences) was given to the students.

\section{- Statistical analysis}

To analyze the collected data, the researcher used means, standard deviation, ANOVA, and Tukey Multiple Comparison for the Means.

\section{- Findings of the studv}

This study aimed at investigating the effectiveness of using keyword and semantic mapping strategies on the learning and retention of vocabulary items of the tenth-grade students.

\section{7}


More specifically, the study tried to find out if there were any significant differences between the learning's tests mean scores of the three groups due to the effect of using vocabulary teaching strategies. Also, it tried to explore any significant differences between the retention test mean scores of the three group attributed to the time span. The findings regarding the three research questions are summarized in the following paragraphs:

Tables 1, 2, 3 and 4 present the answer to the first and second questions concerning to what extent the tenth-grade students' use of keyword strategy and semantic mapping affects their learning of vocabulary items either immediately or after two weeks.

Table (1): Mean Scores and Standard Deviation of all the three groups on Learning Test

\begin{tabular}{|l|l|l|l|}
\hline Strategy group & N & Mean & Std.Dev \\
\hline (Learning) Keyword & 30 & 91.83 & 20.320 \\
Semantic mapping & 30 & 80.67 & 18.039 \\
( control ) & 30 & 78.50 & 20.263 \\
Total & 90 & 83.67 & 20.221 \\
\hline
\end{tabular}

It is clear from Table 1 that there were differences between the mean scores of students in both experimental groups and the control group. As can be seen from Table 1, the keyword group acquired more vocabulary items than the other strategies groups in the learning test. To test whether these differences were significant, One-Way ANOVA was used. The results are shown in Table 2.

Table (2): One - way ANOVA for the difference between mean scores of the two experimental groups and the control group on the learning test.

\begin{tabular}{|l|l|l|l|l|l|}
\cline { 2 - 6 } \multicolumn{1}{c|}{} & Sun of sq & Df & Mean of sq & F & Sig. \\
\hline (Learning) between & 307.667 & 2 & 1535.833 & 4.010 & .022 \\
groups & 33318.333 & 87 & 382.969 & & \\
Within groups & 36390.000 & 89 & & & \\
Total & & & & & \\
\hline
\end{tabular}

As it is clearly indicated in Table 2, there was a significant difference among the three groups in the learning test.

Table (3): Mean Scores and Standard Deviation of all the three groups on Retention Test

\begin{tabular}{|l|l|l|l|}
\hline Strategy group & N & Mean & Std.Dev \\
\hline (RET) keyword & 30 & 84.33 & 16.281 \\
\hline Semantic mapping & 30 & 78.33 & 21.906 \\
\hline Traditional (control) & 30 & 72.83 & 24.449 \\
\hline Total & 90 & 78.50 & 21.443 \\
\hline
\end{tabular}


Table 3 indicates there was a difference between the mean scores of students in both experimental groups and the control groups in the Retention test. To test whether this difference was significant, OneWay ANOVA was used. The results are shown in Table 4.

Table (4): One - Way ANOVA for the differences between mean scores of the two experimental groups and control groups on the retention test.

\begin{tabular}{|l|l|l|l|l|l|}
\cline { 2 - 6 } \multicolumn{1}{c|}{} & Sun of sq & Df & Mean of sq & F & Sig. \\
\hline (RET) between groups & 1985.000 & 2 & 992.500 & 2.218 .155 \\
Within groups & 38937.500 & 87 & 447.557 & & \\
Total & 40922.500 & 89 & & \multicolumn{2}{c|}{} \\
\hline
\end{tabular}

As it is clearly indicated in Table 4, there was a significant difference among the three groups in the learning test.

Concerning the third question about whether there was a statistically significant difference between teaching words using keyword and semantic mapping on students' learning and retention of vocabulary items either immediately or after two weeks, Tukey's post hoc procedure was used to examine the comparison among the three groups strategies means in the learning test. The findings of the comparison are shown in Table 5.

Table (5): Tukey's Multiple Comparison for the Means of the three learning test among the three groups

\begin{tabular}{|l|l|l|l|}
\hline (1) Group & (J) Group & $\begin{array}{l}\text { Mean Dif } \\
(1-\mathrm{J})\end{array}$ & Sig \\
\hline Key word & Semantic mapping & 11.17 & .075 \\
& Control & $13.33^{*}$ & .026 \\
\hline Semantic Mapping & Keyword & -11.17 & .075 \\
& Control & 2.17 & .904 \\
\hline control & Keyword & $-13.33^{*}$ & .026 \\
& Semantic mapping & -2.17 & .904 \\
\hline
\end{tabular}

*The mean differences is significant at the 0.05 level

It is evident from Table 5 that there was a significant difference among the keyword strategy, the semantic mapping strategy, and the control group in favor of the keyword strategy in the learning test.

To sum up, the results of the study showed that the keyword strategy and semantic mapping strategy had better effect on students' acquisition of the vocabulary items than the traditional strategy. The keyword strategy in particular had more effect than the semantic mapping on the students' acquisition of the vocabulary items. Moreover, there was no significant difference between the mean

\section{9}

Journal of Arabic Studies in Education \& Psychology (ASEP) 
scores of both strategies: keyword and semantic mapping on the retention test due to the vocabulary strategy. Finally, the findings revealed significant differences in the students' mean scores of the acquisition test in favor of the experimental groups and particularly in favor of the keyword strategy.

\section{- Discussion, pedagogical implications and recommendations}

- Discussion

The findings of the study show that the keyword strategy group performed better than the control group in the learning test (immediate test). This conclusion is in agreement with Raugh and Atkinson, 1975; Pressley et al., 1985. McDaniel et al., 1987, Brown and Perry, 1991; Wang and Thomas, 1992; Levin et al, 1992. However, these findings were inconsistent, with the findings of Willerman and Melvin (1979), Hogban and Lawson (1994), Hell and Mahn (1997), and Rodriguez and Sadonski (2000) who found that the keyword strategy had no effect on learning vocabulary items.

The study also revealed that there was no significant difference between the experimental groups in the retention test after two weeks from the treatment. These results were consistent with some studies, for example, (Willerman \& Melvin, 1979, Hogban \& Lawson, 1994; Hell and Mahn, 1997; and Rodriguez and Sadoski, 2000) in which keyword strategy had no effect on the retrieval of vocabulary items.

Concerning the semantic mapping strategy, the study revealed that this strategy was less effective than the keyword strategy but higher than the control group in learning the vocabulary items immediately after the instruction. The study also showed that there was no significant difference between the semantic mapping and the other strategies in the retention test which was taken after two weeks from the treatment. This conclusion was in agreement with Zakaria (2001) in which the semantic mapping had a noticeable and positive effect on vocabulary items learning and retention.

The possible explanations of the previous findings can be due to the following points. Firstly, it seems that the keyword strategy strengthens the link between the target words and their meanings. The keyword strategy does this verbally and through imagery (in this study, the sentences depicting the interactive images used in the keyword strategy seem to have positively affected the processing of memorizing the words). Secondly, using the standard Arabic (keywords) in the keyword strategy affects positively the links and the association between the target words and their Arabic translation. Thirdly, the fact that the Keyword strategy does not require a high

\section{0}


level of cognitive effort motivates students' learning of the lexical items. Finally, the foreign language learners adapt the Keyword Strategy easily (Brown and Perry, 1991). According to semantic mapping strategy, it seems to be that if the teachers of English Know how and when to use semantic mapping strategy, it can serve to facilitate vocabulary learning.

In conclusion, the previous results provide evidence that the Keyword Strategy is an effective strategy to use in teaching vocabulary items. They proved that the semantic mapping strategy is a less efficient strategy for the tenth grade students in the sense that it does not promote vocabulary learning in comparison with the Keyword Strategy but it promotes vocabulary learning better than the control group. Generally speaking, the findings showed that the two strategies (keyword and semantic mapping) facilitate the learning and retrieving of new foreign language vocabulary words.

\section{- Pedagogical Implications}

There is a value in use of vocabulary teaching strategies for learning foreign lexical items. It is argued that learners encounter many specific problems in the process of foreign language vocabulary learning and so the use of various strategies is recommended. EFL teachers should give greater recognition to the importance of strategy training, introduce various vocabulary teaching strategies, and encourage the use of the strategies in order to enhance learners' vocabulary learning. EFL learners should be trained in the use of various vocabulary strategies. EFL teachers should choose the appropriate vocabulary strategy that suits the learners' levels. Even the curriculum designers should include the various vocabulary strategies as semantic mapping and Keyword in the curricula. This study demonstrates that the students benefit from the Keyword and semantic mapping strategies in learning and retrieving unfamiliar words.

\section{- Recommendations}

This research has demonstrated the effectiveness of the Keyword and semantic mapping strategies on foreign students' vocabulary learning. There will be much more studies in the future research on the vocabulary strategies if the following considerations are taken.

1. More studies on the effectiveness of the keyword and semantic mapping strategies can be conducted among Jordanian students. It

\section{1}

Journal of Arabic Studies in Education \& Psychology (ASEP) 
seems that most studies examining the superiority and success of the keyword and semantic mapping strategies conducted on nonArab students.

2. It would be recommended to enlarge the scale. That is, examining a large number of students. The obtained results could show more generalized and representative image or scenes about the efficacy of the keyword and semantic mapping strategies among Arab students. Studies could be conducted on low basic stage and university level. It is worthwhile to examine the efficiency of the keyword and semantic mapping strategies on students of different ages and levels of language proficiency.

3. To prove the effect of keyword and semantic mapping strategies on vocabulary learning, more studies on their success on different groups of vocabulary verbs, nouns, and function words, are needed.

4. Studies can be conducted to examine the effectiveness of keyword and semantic mapping strategies on different types of word knowledge. It is believed that in order to know a word, the kind of knowledge that a learner must master include: the meaning of the word, the spoken form of the word, and the frequency of the word.

\section{- $\underline{\text { References }}$}

- Abdel-Majeed , M.M .(2000). The keyword method: A powerful memory aid to vocabulary learning in the EFL classroom. The E.R. Journal, 17,9-27.

- Abo-Khadrah, Q.A.I. (1995). A comparison of various EFL vocabulary learning strategies among tenth graders. An Unpublished M.A Thesis, Yarmouk University.

- Alber, S.R., and Foil,C.R. (2002). Fun and effective ways to build your students' vocabulary. Intervention in School and Clinic, $37,131,139$.

- Atkinson, R.C., and Raugh, M.R. (1975). An application of the mnemonic keyword method to the acquisition of a Russian vocabulary. Journal of Experimental psychology: Human Learning \& Memory, 104(2), 126-133.

- Avila, E. \& Sadoski, M. (1996). Exploring new applications of the keyword method to acquire English vocabulary. Language Learning, 43(3),379-395

\section{2}


- Brown, T.S., \& Perry, F.L.J. (1991). A comparison of three learning strategies for ESL: Vocabulary acquisition. TESOL Quarterly, 25(4),655-670.

- Brown, C. \& Payne, M.E. (1994). Five essential steps of processes in vocabulary learning. Paper presented at the TESOL Convention, Baltimore, $M D$.

- Condus, M.M., Marshall, K.-J. \& Miller, S.R. (1986). Effects of the keyword mnemonic strategy on vocabulary acquisition and maintenance by learning disabled children. Journal of Learning Disabilities , 19(10), 609-13.

- Cook, V. (1996). Second language learning and language teaching. (2nd Ed.), Edward Arnold (Publishers) Limited.

- Coughlin, J. K. (1989). Recent developments in interactive and communicative CALL: Hypermedia and "Intelligent" Systems.

- Desrochers, A. \& Begg, I. (1987). A theoretical account of encoding and retrieval processes in the use of imagery-based mnemonic techniques: The special case of the Keyword method, imagery and related mnemonic processes theories, individual differences and application. In M.A .McDaniel \& M. Presley (Eds.), Imagery and related mnemonic processes: Theories, individual differences and applications. New York: Springer.

- Gray, W. \& Eleanor H. (1939). The development of Chicago meaning vocabularies in reading . Chicago: University of Chicago Press.

- Guey, C, Cheng, Y. \& Huang, L. (n.d) . Effect of keyword method on memory of word groups for Chinese learning of English. Retrieved November 2, 2005, from http:// www.hiceducation.org.

- Hall, J, W. (1988). On the utility of the keyword mnemonic for vocabulary learning. Journal of Educational Psychology, 80(4), 554-562

- Hanf, M.P. (1971). Mapping: A technique for translating reading into thinking. Journal of Reading, 14,225-230,270.

- Hogban, D. \& Lawson, M.J. (1994). Keyword and multiple elaboration strategies for vocabulary acquisition in foreign language learning. Contemporary Educational Psychology, 19,367-376. 
- Johnson, C.W., Adams, M., \& Bruning, R. (1985). Keywords and vocabulary acquisition: Some words of caution about words of assistance. Educational Communication and Technology Journal, 33,125-138.

- Johnson, D.D. \& P.D. Pearson. (1984). Teaching reading vocabulary, (2nd ed). New York: Holt, Rinehart and Winston.

- Krashen, S.D., \& Terrell, T.D. (1983). The natural approach. England Cliffs, NJ: Alemany Press. Regents/Prentice Hall.

- Laufer, B. (1997). The lexical plight in second language. In J. Coady, \& T. Huckin, Second language vocabulary acquisition. Cambridge: Cambridge University press.

- Levin, J.R., Levin, M.E., Glasman, L.D. \& Nordwall, M.B. (1992). Mnemonic vocabulary instruction: Additional effectiveness evidence. Contemporary Educational Psychology, 17(2),156-174.

- Levin, J.R. Johnson., Pittelman, S.D., Levin, K.M.,Shriberg, L.K., Toms- Bronowski,S., \& Hayes,B.L. (1984). A comparison of semantic and mnemonic-based vocabulary learning strategies. Reading Psychology, 5, 1-15.

- McDaniel, M.A., Pressley, M. \& Dunay, P.K. (1987). Long term retention of vocabulary after keyword and context learning. Journal of Educational Psychology, 79, 87-92.

- Mckeown, M. G. \& Beck, I.L. (1988). Learning vocabulary: Different ways for different goals. Remedial and Special Education,9,16.

- Meara, P. (1992). EFL vocabulary tests. Unpublished manuscript, Centre for Applied Language Studies, University College, Swansea, UK.

- Mezynski, K. (1983). Issues concerning the acquisition of knowledge.

- Ministry of Education in Jordan (2005). Teacher's Book-Tenth Grade.

- Moore, M. \& Calvert, S. (2000). Brief report. Vocabulary acquisition for children with autism: Teacher or computer instruction. Journal of Autism and Developmental Disorders, 30,359-362. 
- Morin, R. \& Goebel, J. (2001). Basic vocabulary instruction: Teaching strategies or teaching words? Foreign Language Annals, 1,8-17.

- Nagy, W. (1997). On the role of context in L1 and L2 vocabulary learning in vocabulary description, acquisition and pedagogy. New York: Cambridge University Press .

- Nation, I,S.P, (2001). Learning vocabulary in another language. Cambridge: Cambridge University Press.

- Nunan, D. (1990). Second language teaching and learning. Boston, Massachusetts: Heinle Publishers.

- Pawley, A. \& Syder, (1983) . Two puzzler for linguistic theory: Native-like selection and native-like fluency. In J .Richards and R. Schmidt (Eds.), Language and communication. London: Longman.

- Pressley, M., Levin, J.R., Digdon, N., Bryant, S. \& Ray, K. (1983). Does method of item presentation affect keyword method effectiveness?. Journal of Educational Psychology, 75, 686-691.

- Pressley, M., Levin, J. \& Delaney, H.D. (1982). The mnemonic keyword method. Review of Educational Research, 52(1), 61-91.

- Pressley, M., Levin, J.R., Hall, J.W., Miller, G.E.\& Berry, J.K. (1980). The keyword method and foreign word acquisition. Journal of Experimental Psychology, 6,163-173.

- Raugh, M.R. \& Atkinson, R.C. (1975). A mnemonic method for learning a second-language vocabulary. Journal of Educational Psychology, 67,1-16.

- Rodriguez, M. \& Sadoski, M. (2000). Effect of rote, context, keyword, and context/ keyword methods on retention of vocabulary in EFL classroom. Language Learning, 50(2),385-412.

- Rupley, W. H,. Logan, J.W. \& Nichols, W. D . (1999). Vocabulary instruction in a balanced reading program. Reading Teacher, 52 (4) 336-337.

- Trout, E.D. (1986). Evaluation of the keyword mnemonic method for acquisition and retention of medical terminology. Unpublished $P h D$. Dissertation. University of Southern IIIinois University at Carbondale.

\section{5}


- Van Hell. J.G. \& Candia Mahn, A.C. (1997). Keyword mnemonics versus rote rehearsal: Learning concrete and abstract foreign words by experienced and inexperienced learners. Language Learning, 47,3 507-546.

- Wang, A.Y. \& Thomas , M.H . (1992). The effect of imagerybased mnemonics on the long-term retention of Chinese chargers. Language Learning, 42, 359-376.

- Watanabe, Y. (1997). Input, intake, and retention: Effects of increased processing on incidental learning of foreign language vocabulary . Studies in Second Language Acquisition, 19(3), 287307.

- Willerman, B. \& Melvin, B. (1979) . Reservation about the keyword mnemonic. The Canadian Modern language Review,35(3), 443-453.

- Zakaria, H. (n.d.) The use of semantic mapping in aiding reading comprehension, Retrieved October 16, 2005, from http://www. eltrec.ukm./

\section{潾潾潾潾}

